Volume 1

Issue 1 Fall

Article 15

October 1973

\title{
Theoretical. Perspectives on the Analysis and Development of Social Policies
}

David C. Gil

Brandeis University

Follow this and additional works at: https://scholarworks.wmich.edu/jssw

Part of the Social Work Commons, and the Sociology Commons

\section{Recommended Citation}

Gil, David C. (1973) "Theoretical. Perspectives on the Analysis and Development of Social Policies," The Journal of Sociology \& Social Welfare: Vol. 1 : Iss. 1 , Article 15.

Available at: https://scholarworks.wmich.edu/jssw/vol1/iss1/15

This Article is brought to you by the Western Michigan University School of Social Work. For more information, please contactwmu-scholarworks@wmich.edu.

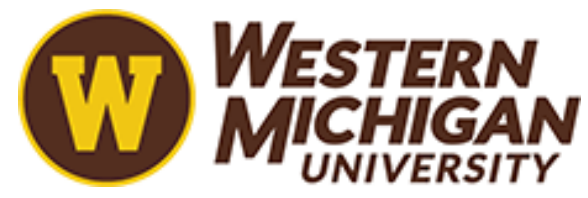




\section{meroReTICAX PERSPECTIVES ON THE ANAIYSIS AND DEVELOPMENT \\ OF SOCIAL POLICIES* \\ David G. Gil \\ Brandeis University}

\section{Introduction}

The development of social policies, in American and in many other societies, usualiy proceeds in fragmented fashion in relation to different substantive issues such as economic security, housing, education, physical and mental health, social deviance, child and family welfare, aging, intergroup relations, etc. The fragmentary nature of processes of social policy formulation reflects their political nature and their roots in conflicts of real or perceived interests among diverse social groups. Were existing processes of policy development to result in social orders in which all members of a society could lead meaningful and satisfying lives, there would be little reason to explore alternative approaches. Since, however, conditions of life of large segments of many societies continue to be unsatisfactory in many respects and in varying degrees, it seems imperative to search for more constructive and effective approaches to the analysis and development of social policies, and to explore potential contributions of social theory to the design of such alternative approaches. The present paper is one contribution to this search.

Analysis and development of social policies seem to be hindered at present not only by their political contest, but also by inadequate comprehension of the generic function and dymaics of social policies, and of the principal variables through which these policies operate. There is, in fact, no agreement among policy analysts concerning the very meaning of the concept "social policies". To overcome these theoretical difficulties, this paper suggests a universally valid conceptual model of social policies. This is expected to enhance understanding of the general functions and dynamics of all social policies, factiltate the analysis of specific policies and their consequences, and aid in the development of altermative policies.

Implied in the general model presented below is the assumption that all those policies known as "social" are concerned with an identical underlying domain of societal existence, and are operating through the same basic processes, in spite of considerable variation in the substantive content, objectives, and scope of specific social policies. It follows that they are not independent, but interact wth each other. A11 extant social policies of a given society are thus to be viewed as constituting a comprehensive system, which influences the common domain through its aggregate effects. Every specific social policy Influences

* This paper is reprinted with permission of International Social Work where it was published in Vol. XV, No.3, 1972. The paper was developed early in 1971 within the Social Policy Study Program stpported by the Office of Child Development, H.E.W., at Brandeis University (PR-288-1). The concepts and approach discussed in this paper are developed further in the author's book, Unravelling Social Policy - Theory, Analysis, and and Political Action Towards Social Bquality, Cambridge, MA: Schenkman Publishing Company, 1973. 
a certain aegment of the general domain and thus contributer to the egoregate effect. It should be noted, however, that while all social policies are thus viewed as components of one system with reference to their underIyIng common domain, they are not necessarily assumed to be consistent with each other. Rather, considerable inconsistency tends to prevail among these policies because of their origin in conflicts of interests among a society" $\mathrm{g}$ sub-segments.

The Common Domain of Social Policies

Comparative, cross-cultural studies of "social policies", in American society and others throughout the world, and throughout the history of mankind, suggest that, despite variety in substance and scope, all such policies are indeed concerned with an underlying comon domain. Whether in a concrete and specific sense these policies deal with economic assistance to the poor; levging of taxes; protection of chlldren, the aging, or the handicapped; training of manpower and regulation of working conditions; provision of housing, health care, and education; prevention and control of crime, and rehabilitation of offenders; protection of consumers; regulation of industry, commerce, and agriculture; preservation of natural resources, etc., in an abstract and general sense they are all dealing with one or more of the following interrelated elements of societal existence:

a. the overall quality of life in a society;

b. the circumstances of living of individuals and groups; and

c. the nature of intra-societal human relations among individuals, groups, and society as a whole.

These elements constitute, therefore, the general sphere of concern, the comon domain, or, in systems terms, the "output" of a society's system of social policies. They are consequently the core-elements of the proposed, universally valid conceptual model of all social policies. There is ample evidence that every human society designs policies to shape or "regulate" this general domaln. Indeed, no human society could survive for long if it left the regulation of this domain to the forces of nature and of chance events, and did not attempt to influence it consistently through man-designed measures.

It should be noted also that economic factors are intrinsic aspects of the common domain of social policies as defined here, since they are important determinants of the overall quality of 1ife in a society, the circumstances of living of its members, and their relations to each other and to society as a whole. Economic policies are included among "social policies" as they are important means for attaining ends in the social policy domain. By including economic issues within the domain of social policies, the widespread conceptual confusion resulting from the arbitrary division between economic and social policies can be avolded.

The Rey Processes of Social Policies

Having identified the common domain of all social policies, the general processes by which social policies influence this domain must now be explained. These processes constitute the dynamic components of the concep- 
Involve little or no modification of these key variables and their interactions can therefore not be expected to result in significant changes of a given status quo with respect to the quality and the circumstances of life and the human relations in a society. Anti-poverty policies during the sixties in American society are telling illustrations of this obvious fact. These policies introduced merely minor changes in resource development and in the distribution of rights and the allocation of statuses to deprived segments of the population, and thus failed to produce the promised changes in the quality and circumstances of 1 ife and in humen relations. They turned out to be merely new variations on an old theme.

It should also be noted that "social problems" perceived by various groups in a society concerning the quality and the circumstances of life, or intra-societal human relations, must be understood as intended or unintended consequences of the existing configuration of social policies. Such policies are therefore viewed not only as potential solutions to specified social problems, but all past and extant social policies of a society are considered to be causaliy related to the various social problems perceived by its members at any point in time. This conceptualization of the relationship between social policies and social problems does not negate the significance of specific policies as potentiai solutions to percelved problems. Rather, it provides an expanded theoretical basis for the proposition that valid solutions of social problems require approprinte modifications of the key processes of social policies. Such modifications are viewed as potentially powerful instruments of planned, conprehensive and systematic social change, rather than merely as reactive measures designed to amellorate specified undesirable phenomena in an ad hoc, fragmented fashion.

Limitations of space prevent further discussion and illustration of the theoretical and practical aspects of the keg elements of the conceptual model of social policies and of their interactions. However, some observations seem essential concerning the linkage between status allocation and rights distribution. Many human societies, including American soclety, distribute many rights as rewards for status incumbency. This Iinkage between the distribution of rights and the allocation of statuses tends to result in considerable inequality of rights anong incumbents of different statuses. It is important to note in this context that while differences in status are clearly an essential aspect of task organization in a society, once division of labor has been adopted in the course of societal evolution, inequality of rights is logicaliy not an essential consequence of stich differences in statuses. Nany societies, including several "socialist" ones, have, however, adopted inequality of rights as if it were an essential corollary of the division of labor, and have institutionalized inequality of rewards for different. statuses. From a theoretical perspective it is, of course, entirely feasible to distribute rights equally among all members of a society by means of universal entitlements, irrespective of status. Such a principle of rights distribution would be reflected in independence of rights and statuses. Any intermediate level of Iinkage between rights distribution and status allocation is theoretically feesible, and can be designed in practice.

The linkage of rights distribution to status allocation is usually rationalized and justified with reference to incentives and human motivation. It is claimed axionatically that in order to recruit personnel for the diversity of statuses in a society, prospective incumbents must be 
tual mode1, for through them and theix derivatives soc1ettes manage to shape the overall quality of life, the circumstances of Iiving, and the nature of human relations. It seems that in spite of apparentiy unlimited diversity of the substantive provisions of social policies of different societies, at different times, they can all be reduced to one or more of the following interrelated universal processes:

1. Development of material or symbolic life-sustaining and 1ifeenhancing resources.

2. Division of labor, or allocation of individuals and groups to specific "statuses" within the total array of societal tasks and functions, involving corresponding roles and prerogatives intrinsic to these roles.

3. Distribution to individuals and groups of specific rights to material and symbolic life-sustaining and life-enhancing resources, goods and services through general or specific entitlements, "status"- specific rewards, and general or specific constraints.

The universality of these key processes derives from their origin in certain intrinsic characteristics of the human condition, namely, man's bio-psychological drive to survive, the necessity to organize human labor in order to obtain scarce life-sustaining resources from the natural enviroment, and the need to devise some system and principles for distributing these 1ife-sustaining resources throughout a society. It is obvious that the overall quality of life of a society depends largely on its interaction with its natural setting and on the quality and quantity of resources, goods and services it generates through investing human labor Into its enviromment. Clearly, also, the circumstances of living of individuals and groups, and their relations with each other and with society as a whole, depend largely on their specific positions or "statuses" withIn the total array of societal tasks and functions, and on their specific share of, or rights to, concrete and symbolic resources within the totality of those avallable for distribution by each soclety. Processes of resources development, status allocation, and rights distribution, and the interactions between these processes are consequently the underlying key varlables of all social policies, and thus constitute the dymamic elements of the proposed conceptual model. The possibilities of variation in the way these processes operate and interact in different societies at different times are numerous, and so are the variations of specific social policies and of entire systems of such policies. Any specific social policy reflects one unique position on one or more of these key variables, and one unique configuration of interaction between them. Changes of policles and of systems of policies depend, therefore, on changes on one or more of these underlying key variables and in the relations between them. Desired modifications in human relations, in the quality of life, and in the circumstances of living can therefore be achieved by means of appropilate modifications of one or more of these key variables of soctal policies. This proposition implies the frequently disregarded corollary that significant changes in human relations and in the quality and the circumstances of life will occur only when a society is willing to introduce significant modifications in the scope and quality of the resources it develops, and in the criteria by wich it allocates statuses and distributes rights to its members. Social policies which 
atracted through incentives built into the reward aystem. While this may be a fairly accurate description of current humn behaviour, it does not explain the sources and dynamics underlying this response pattern, nor does it answer the important question whether this response pattern is biologically determined and thus the only behavioural possibility.

Biological, psychological, and soclological research Indicate that human motivation $1 \mathrm{~s}$ a function of biologically given factors and socially learned tendencies. The relative importance of these two sets of factors is not known, but there seems to be little question that learned tendencies are a powerful force in human behaviour. It therefore seems that exlsting patterns of motivation and incentive response zeflect existing patterns of socialization, and that variations in these socialization patterns could produce over time different motivational attitudes and response patterns. This suggests that the patterns of human motivation used to justify the structured inequalities in the distribution of rights in most existing societles are not fixed by nature, but are open to modification by means of variations in the process of socialization. The view that man responds primarily to the profit motive is not necessarily a correct indication of mankind's social and cultural potential.

The Force Fleld Affecting and Constraining the Evolution of Sociel Policies

The processes of resource development, status allocation, and rights distribution are themselves subject to the influences of certain natural and societal forces. The various forces are identified in Chart 1 on the following page.

The physical and blological characteriatics of a society's natural enviroment are 1 imiting conditions with respect to the development and distribution of 1ife-sustaining resources. Man's ow biological and psychological properties affect his capacities and his motivation, his interaction with other men, and the orgenization of his work, and hence indirectly the key processes of resource development and rights distribution.

Societal forces affecting the evolution of social policies are traceable to man's collective response to the unfversal characteristics of the human condition as sketched above. Over time these responses resulted in the following significent social developments: the evolution of division of labor and of systems of social stratification based on this; the evolution of the principle of unequal rewards linked to different statuses and roles; the emerging interest of individuals and groups in perpetusting advantages accruing to them as a result of the patterned inequalities in the allocation of statuses and the distribution of rights; and the evolution of the principles of storing and accumilating surplus rewards, and trangmitting them to one's offspring.

The emergence and interplay of these principles and tendencies, and the reactions to them of competing interest groups within societies seem to constitute major dynamics of the evolutionary, and at times revolutionary development of human societies and thelr social policies. Social policies may thus be viewed as dynamic expressions of the evolving structures and conflicts of societies; they are derived from them and in turn support the structures and spur the conflicts. Once initiated, the pro- 


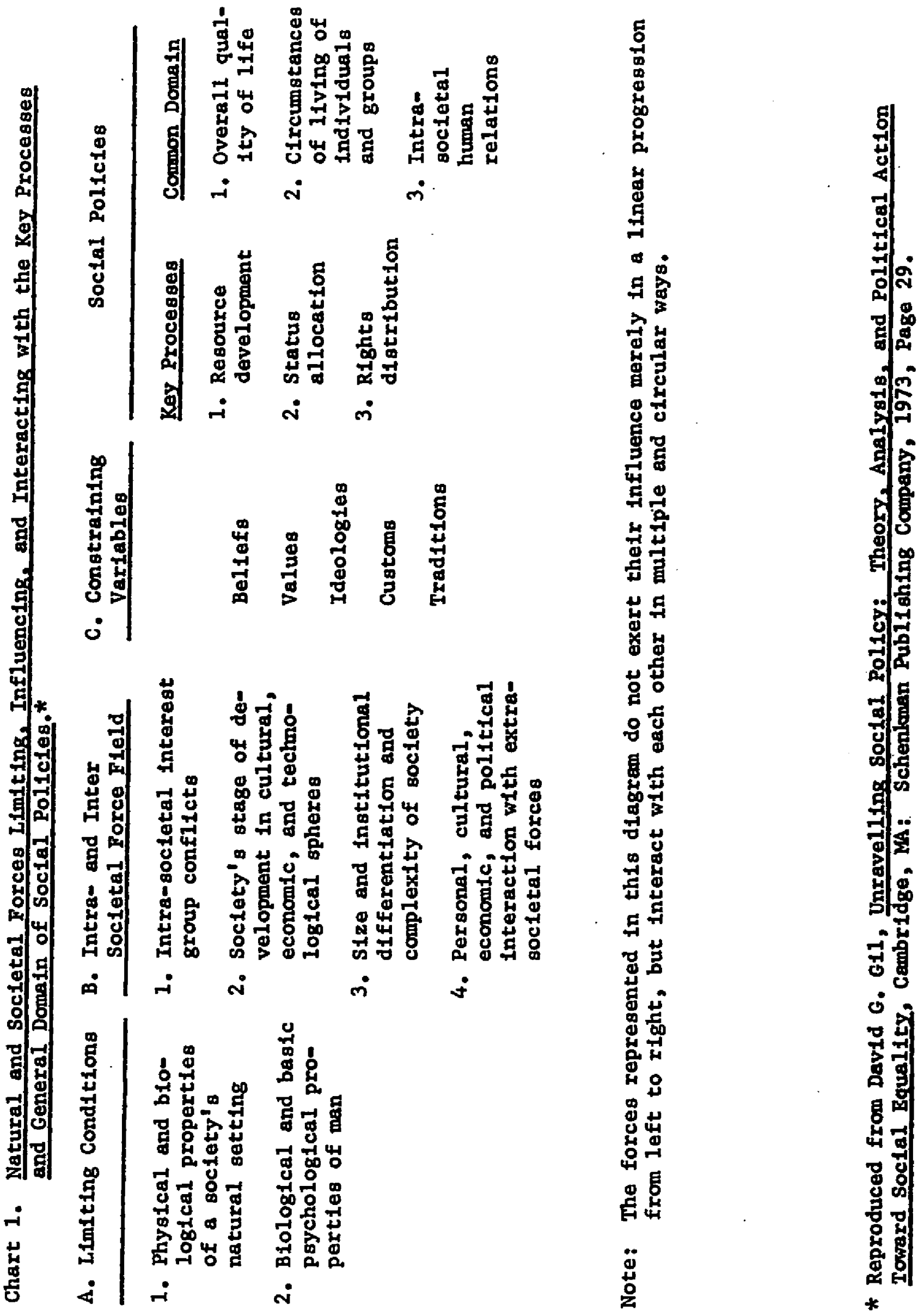


commlted forever to the self-percelved, narrowly conceptualized, shortrange interests of their groups of origin. Cultural elites can and often will develop comprehensive, broadly-based, long-range conceptions of societal interests. There is consequently always a potential for change in the dominant beliefs and values of societies, and in social policies, whose malleability seems limited by them. In any case, it needs to be emphasized in this context that significant changes are not likely to occur in a society's system of social policies without thorough changes in its dominant beliefs and values.

Analysis and Development of Soctal Policies

Having identified the common domain and the key variables of all social policies, as well as the sets of forces which influence and constrain their evolution and implementation implications for their analysis and development can now be explored.

Social policy analysis is viewed here as a systematic scientific process, whose purpose is to obtain valid and reliable information concerning specified societal issues, and the chain of consequences of specific policies designed to deal with them. Social policy development utilizes policy analysis in order to design alternative policies to achieve identical objectives more effectively or efficientiy, or to achieve different objectives dertved from different value premises. Policy evaluation takes place in a political context, which needs to be considered as a significant variable in policy analysis and development, but political processes should not be confused with these, Effectiveness of social and political action can, however, be enhanced through insights derived from the conceptual model in the analysis of social policies.

Valid and reliable analysis of social policies with the aid of a frameworkk derived from the conceptual model requires considerable resources, including analysts competent in the several social and behavioural sciences and knowledgeable about the substantive issues dealt with by specific policies. Access to a variety of data concerning a population is also essential although it may often be sufficlent to carry out abbreviated analyses. However, whether a comprehensive or an abbreviated analysis is conducted, all relevant analytic foc1 derived from the conceptual mode1 and the forcefield surrounding policy evolution should be considered.

Before specific social polfcies can be analyzed or developed or their adequacy evaluated the relevant issues need to be clarified. Issues should be defined whenever possible with reference to the common domain of all social polfcies rather than in terms of specific policies and their provisions.

Policy analysis itself. is te be carried out on three levels: . first on that of substantive policy context, next on the social structural level, and finally on the socletal forcefield level.

The first level of analysis involves specification of overt and covert objectivies with reference to the issues dealt with, of policy-relevant 
cesses of societal evolution, and the paxallel processes of soclal policy evolution, continue as a result of ceaseless conflicts of interest among individuals and social groups who control different levels of resources, and who differ consequently in rights and power. The processes of social policy evolution are also affected by, and in turn affect, a society's stage of development in the cultural, economic, and technological spheres; its size and its level of institutional differentiation and complexity; its interaction with extra-societal forces; and its values, beliefs, customs, and traditions.

Values and Soclal Policies

The dominant bellefs and values of a society and the customs and traditions derived from them exert a significant influence on all decisions concerning the three key processes of social policies. Consequently, any specific configuration of these processes and the resulting systems of social policies tend to reflect the dominant value positions of a society concerning such policy relevant dimensions as individualism--collectivism, competition--collaboration, Inequality--equality, etc. A society's dominant beliefs and values appear thus to constitute crucial constraining variables which limit the malleability of its processes of resource development, status allocation and rights distribution, and of the social po11cies derived from them. Thus, a society which stresses individualism, purguit of self-interest, and competitiveness, and which hes come to consider inequality of circumstances of living and of rights as a natural order of humen existence, will tend to preserve structured inequalities through its processes of status allocation and rights distribution, while one which stresses collective values and cooperation and which is truly committed to the early American notion that "all men are created equal", will tend to develop a system of policles wich assure to all its members equal access to all statuses, and equal rights to material and symbolic Iffe-sustaining and life-enhancing resources, goods, and services.

While drelling briefly on the central importance of beliefs and values for social policy analysis and development, it should be noted that public discussion of such policies in the United States tends to neglect this crucial variable. Instead, ajor, and often exclusive, emphasis tends to be placed on technical matters and on means, whtle the goals and values aimed at are pushed to the background. These comments should not be misunderstood. Technical matters are indeed important, and alternative menns need to be evaluated in tems of effectiveness and efficiency. However, unless gosis and values are clear, and are constantly kept in mind as main criteria for policy evaluation and development, the examinstion of means and of technologies 18 merely an exercise in futility.

While beliefs, values, customs, and traditions are not fixed forever In any human society, changing them is usually not a simple matter. The dominant beliefs and values of societies tend to be shaped and guarded by cultural and political elites, recruited mainly from among their more powerful and privileged strata. Not unexpectedly, these beliefs and values seem, therefore, to reflect and support the interests of these nore powerful and privileged social groups. It should be noted, however, that some members of cultural and political elites are recruited from less privileged strata and may represent their interests. Also, not all those members who originated in more privileged social groups are necessarily 
value prentees undarlying thege objectives, and of theortes underlytng the otrategy and the substantive provisions of a policy. This level 3180 involves description of target segments of the population in qual1tative and quantative terms, and exploration of short-and long-range intended and unintended effects on target and non-target segments of the population. Finally, this level examines the extent to which policy obfectives are being realized, and the overall costs and benefits of policy implementation.

The second level of analysis is derived from the conceptual model of social policles and is designed to discern implications of a policy for the structure of a society and for its entire system of social policies. It therefore aims to identify changes due to the policy in a soctety's development of resources, in the criteria it uses for otatus allocation and rights distribution, in the overall quality of life, in the circumstances of living of Individuals and groups, and in the quality of human relations among its members.

The third level of analysis explores interaction effects between specific policies and the forces surrounding their development and implementation*. This is of apecial relevance for predicting the fate of given policies within a given socletal context. It also reviews the history of a policy and the political forces in a soclety which promote or resist it.

Utilizing the conceptual model of social policies in the development of alternative policies involves determination of the nature and scope of changes which must be made in the key policy variables of resource development, status allocation, and rights distribution in order to attain selected policy objectives. These changes are then transformed into substantive program elements and are incorporated into nesly generated policies. It should be emphasized again that specified policy objectives depend for their realization on specific configurations of the manner of operation of the key variables and that unless these configurations are attalned by means of approprlate modifications of such varlables the objectives can simply not be realized.

This abstract statement can be 111ustrated by a concrete example, namely, the repeated fallures of policies which attempt to eliminate poverty in the United States without algnificantly modifying the configurations of key variables, of which poverty is an inescapable consequence. Poverty is viewed in this context as an income and waith diatribution which Iimits certain segments of the population to levels of command over resources, goods, and gervices below a level defined as "gufficient" by soclety. In the United States this level of sufficiency is measured by the Bureau of Labor Statistics through its "Standard of Living" series. On this gtandard the level of annual income necesgary to maintain a "low" standard of living for a family of four in the spring of 1970 was close to $\$ 7,000$. Obvlously poverty, as defined here, can be eliminated only by social policies which result in redistribution of purchasing power, or of access to services and provisfons, so that all families would reach at least the level of the BLS low standard of living. Polfcies which do not aim to achieve this scope of redistribution of income and wealth-related rights will do many things, but will keep poverty and its destructive side effects intact. 


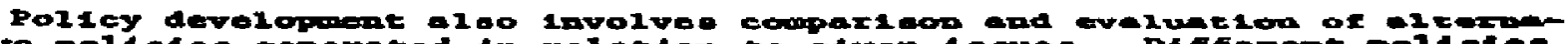
tive poilcies generated in relation to given leoues. Different poilcie. should be examined in terms of value premfoes, Intended effects, the extent to which objectives are attalned, Implications for social otructure and for the entire oystem of soclal policy, unintended effects, and overall costs and benefits. On the basis of these comparisons and evaluations, preferred policles can be selected in terms of specifled criteria which will obviously depend on ones value premises and politicsl objectives.
\end{abstract}

\title{
Implications for Social and Political Action
}

In conclusion, let us consider the implications for social and political action of the theoretical position presented here. Social policies of a society are the product of continuous interaction among a complex set of forces, no one of which can be identified as the primary causal set. Soclal and political action aimed at changing the "soclal policy output" of a society can therefore be directed justifiably at any one of the contributing set of forces. Different intervention theories and the philosophical premises of different change-oriented individuals and groups w11 therefore lead to different intervention strategies.

One appropriate focus for intervention in terms of a non-violent change strategy, based on man's capacity for ressoned judgement of verifiable facts, is the system of beliefs and values of a society. It has been suggested earlier that such values exert a constraining influence on the malleability of its social policy oystem. Therefore, if polfcy changes are sought beyond the range set by existing value premises, these premises need to undergo change 80 as to widen the scope of pollcy options.

Changing a soclety's dominant value premises is, of course, a complicated undertaking at best, since these values pervade all a spects of its culture, its institutional structure and its system of socialization. Social and behavioural sclences offer only uncertain guiding principles for value change. However, self-interest, as perceived by the majority of a population, probably provides energy for maintaining, as well as for modifying, a society's system of values. Changes in dominant values way therefore follow changes in the perceptions of self-interest of large segments of a society. Accordingly, a crucial issue to be raised and examined by groups interested in radical change of the American social policy system by way of thorough modifications of its dominant value premibes, is whether the existing premises are conducive to the realization of the self-interest of the American people. Major policy-relevant values in this context are the cowntment to rugged individualiom, competitiveness, and inequality of rights and opportuntiles. Characteristic features of the policy gystem reflecting these value commitments are attitudes and practices of exploitation towards the natural enviroment and towards human beings, inequalities in circumstances of living of members and groups of society, and a high incidence of alienation in human experience and relations. So the question is whether these values and these polfcles serve the true interests of Americans. These values and policies obviously fall to serve the interests of deprived segments of the population. Their very state of deprivation and exploitation provides sufficient evidence, their ow perceptions notwithstanding. The question is consequently reduced to a consideration of the self-interest of privileged
segments of the population. 
within the organizations for which they work. To explore the interesting Implications of this concept would lead, however, beyond the scope of this paper.

\section{APPENDIX \\ FRAMEWORR FOR SOCIAL POLICY ANALYSIS AND SYNTHESIS}

Section A: The Issues Dealt with by the Policy

1. Nature, scope and distribution of the issues

2. Causal theory(ies) or hypothesis(es) concerning the dynamics of the issues

Section B: Objectives, Value Premises, Theoretical Positions, Target Segments and Substantive Effects of the Policy

1. Policy objectives

2. Value prenises and ideological orientation underlying the policy objectives

3. Theory or hypothesis underlying the strategy and the substantive provisions of the policy

4. Target segment(s) of society--those at whom the policy is aimed:

a. Ecological, demographic, biological, psychological, social, economic, political, and cultural characteristics

b. Numerical size of relevant sub-groups and of entire target segment(s) projected over time

5. Short- and long-range effects of the policy on target and nontarget segment(s) of the society in ecological, demographic, biological, psychological, social, economic, political, and cultural spheres:

a. Intended effects and extent of attaiment of policy objectives

b. Unintended effects

c. Overall costs and benefits

Section C: Implications of the Pollcy for the Rey Processes and the Common Domain of Social Pollcies

1. Changes in the development of Iife-sustaining and life-enhancing material and symbollc resources, goods and services:

a. qualitetive changes

b. quantitative changes

c. changes in priorities

2. Changes in the allocation of individuals and groups, to specific statuses whin the total array of societal tasks and functions:

a. Development of new statuses, roles, and prerogatives

b. Strengthening and protection of existing statuses, roles, and prerogatives

c. Elimination of existing statuses, roles, and prerogatives

d. Changes in the criteria and procedures for selection and assignment of individuals and groups to statuses

3. Changes in the distribution of rights to individuals and groups:

a. Changes in the quality and quantity of general and specific entitlements,' status-specific rewards, and general and specific constraints. 
Before considering, however, the extent of realization of belf-intereat among the privileged, it may help to get some sense of the scope of deprivation in America's affluent society. If one uses the BLs low standard of living as a rough index. of deprivation, one finds that approximately one-third of the American population is deprived in a material sense, for their purchasing power is below the BLS low standard of 1iving. Furthermore, over half of the population Iive on incomes below the BLS "intermediate" standard, which in 1970 was $\$ 10,664$. No doubt then the real self-interests of the majority of the population, the deprived and neardeprived segments, would benefit from policy changes aimed at eliminating their deprived circumstances by truly equalizing rights and opportumities for al1.

Turning to the roughly $40 \%$ of the population who constitute the nondeprived and privileged segments, one soon realizes that material affluence in itself does not assure a satisfactory quality of life and realization of self-interest. The American middle and upper classes seem to be in a stage of social and cultural crisis. This statement could be supported with ample evidence, but space and time being limited it should suffice to mention the serious drug problems and the alienation and revolt of middle and upper class youth. These are, no doubt, symptoms of a gemeration In crisis. The conclusion suggested is that America's privileged classes fail under current conditions to realize their true self-interest, just as the deprived classes fail to realize theirs. The existing system of social policies and its underlying value premises seem to have destructive consequences for all segments of society. Accordingly, major changes in values and in the social policies derived from them would seem to be in the true interest of the whole society. The conmitment to rugged individualism, coupetitiveness and inequality seem detrimental to the wellbeing of all, the deprived and the privileged, and those in between.

This brief analysis suggests that groups interested in non-violent, yet radical, change of values and policies should engage in active political interpretation and education intended to clarify the real underlying human interests of the vast majority, and perhaps the entire population. Such political education would have to be factual and honest, rather than manipulative in the sense of building coalitions and gaining political support on false premises by means of inadequate information and limited comprehension of reality, and on an emotional, non-rational basis.

Our tentative conclusion is that workers in human service fields may choose to redefine their intervention role as political education, irrespective of the settings in which they function. This conclusion seems unavoidable if one realizes that soctal problems are the products of extant social policies, which must be changed radically if the problems are to be eradicated, that changing these policies requires changing society's value premises, and such change depends in turn on revisions in the perceptions of the majority of. the population with respect to their true selfinterest. Redefining the role of human services personnel as agents of political education raises the possibility of conflict between them and their employing organizations, all of which are linked to the existing social system, its policies and its value premises. The solution to this dilemma derives from the concept of individual responsibility for ethical action. This means that those who wish to assume the function of political education must become focal points of an emerging counter-culture 